\title{
Realization of Full Acquisition of Renewable Energy Based on Quota System
}

\author{
Zhiming Xie ${ }^{*}$ and Yuan Zhang \\ School of economics \& management, Changsha Science \& Technology University, P.R. China, 410114 \\ ${ }^{*}$ Corresponding author
}

\begin{abstract}
Feed-in tariffs (FIT) is good for renewable energy (RE) power producers, expanding the scale of RE's development. However, it is unfavorable to RE power grid companies' acquisition, so leading to a serious phenomenon of abandoned wind, solar and water energy. Now this article introduces Quota System, that is Renewable Portfolio Standard (RPS), combining with relevant supporting policies to inspire the $R E$ power producers and power grid companies to carry out the Full Acquisition police of Renewable Energy.
\end{abstract}

\section{Keywords-RPS; FIT; full acquisition; RE}

\section{INTRODUCTION}

Renewable Energy Law clearly requires that the power grid companies should be fully acquired the Renewable Energy (RE) power, which is a powerful solution to control the change of climate and govern haze, and is also an objective requirement for promoting the construction of ecological civilization (Boqiang Lin, 2010). Measure for the Administration of Guaranteed Acquisition of Renewable Energy Generating Electricity proposes to strengthen the management of the full protection of RE power acquisition and achieve the target of non fossil energy consumption, so that there are rules to follow (The First Financial Daily, 2016). Clearly, China attaches great importance to the development of renewable energy and full purchase, and provides legal protection through the law. In recent years, RE power generation has increased rapidly. However, power grid companies, the transmission linker, consider that the acquisition of RE is a trouble thing for increasing the costs and risks, because of the higher electricity price compared with coal power and the backward construction of outbound channel. In the implementation of full purchase, the abandoned phenomenon of the wind, solar and water is very serious. There were wasting about 20 billion $\mathrm{kw} / \mathrm{h}$ of wind power in 2012 (People's Daily, 2013), equivalent to a waste of 6.7 million tons of standard coal. Economic losses were more than 10 billion. In 2015, there were more than 33 billion $\mathrm{kw} / \mathrm{h}$ threw away of wind power alone. The problem of the full acquisition becomes more and more severe so that we should give more attention on it. Tariff mechanism is the key to achieve the full acquisition by balancing the income and distribution in market (Changyu Ouyang, 2013). Therefore, it is of great practical significance to study the RE price mechanism to implement the full acquisition and build a Beautiful China. At present, there are two tariff mechanism in China, Feed-in tariffs (FIT) and Renewable Portfolio Standard (RPS), which is based on government-led and market-driven separately.

\section{The Connotation AND Present Situation of Full ACQUISITION OF RE}

Renewable Energy Law and Measure for the Administration of Guaranteed Acquisition of Renewable Energy Generating Electricity think the Full Acquisition includes two meanings: First, power grid companies should be fully acquired with power generation within its coverage, which conforms to technical standards for grid-connected power generation projects. Second, providing the minimum amount of RE electricity accounts for the total electricity. But in the current market environment, large-scale RE bring great pressure for power grid companies from the long-distance transport because of system costs, management costs, conventional energy power generation targets and user electricity costs. And the pressure cannot be channeled through rational institutional arrangements. The social environmental value of RE electricity cannot be reflected by the price now, resulting in its price is difficult to compete with conventional energy sources. Externality cannot be internalized. Full acquisition appears extremely entangled in the ideal of the system and the reality of embarrassment.

Wind power is the main source of RE in China. In 2015, the number of new wind turbines and installed capacity of wind power in China (excluding Taiwan) have developed rapidly, but abandoned phenomenon is worrying. The average rate of abandoned was $8 \%$ in 2014 . But the amount of abandoned wind power in 2015 increased to 33.9 billion $\mathrm{kw} / \mathrm{h}$, the highest level in recent years, and the average rate of abandoned was up to $15 \%$. The details are shown in Table I and Figure I.

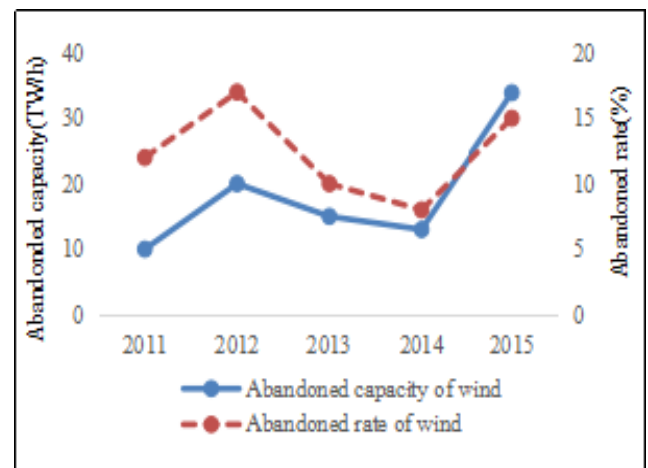

FIGURE I. CHINA'S ABANDONED CAPACITY AND RATE OF WIND IN 2011-2015 
TABLE I. CHINA'S DEVELOPMENT OF WIND IN 2015

\begin{tabular}{|c|c|c|}
\hline Item & $\begin{array}{c}\text { Added and } \\
\text { Cumulative }\end{array}$ & $\begin{array}{c}\text { Growth } \\
\text { Rate }\end{array}$ \\
\hline Added installation of wind turbine (Unit) & 16740 & - \\
\hline Added installed capacity (MW) & 32970 & $32.6 \%$ \\
\hline Cumulative installation of wind turbine (Unit) & 929811 & - \\
\hline Cumulative installed capacity (MW) & 129000 & $12.56 \%$ \\
\hline
\end{tabular}

The most direct reason is that transmission of RE electricity is blocked. Resource-rich areas of China's wind energy and solar energy are reverse distribution with load centers, such as the western low-load areas. The local consumption of RE electricity is limited, so the surplus should be delivered to highload areas by large-scale and long-distance. However, the power grid cannot coordinate perfectly and power transmission channels are difficult to meet the need of RE electricity with the existing power grid construction. The transportation costs are too high to deliver RE electricity. So nobody wants to purchase the extra wind power and photo-voltaic power, resulting in the waste of RE resource and economic losses. If not solve the problem of transmission, the full acquisition of RE power will be difficult.

In addition, the coal-fired power occupies the consumption space of RE electricity. China has proposed the energy development strategies of promoting energy production and consumption revolution in 2014. But it still reserves a considerable space for coal power development in the planning and distribution of the conventional power. Energy Development Strategy Action Plan (2014-2020) has put forward to maintaining coal consumption accounted for $62 \%$ of total consumption in 2020. Table II has shown that even by 2020, coal-fired electricity will still hold the dominant position. The full acquisition of RE will be greatly hampered. The national coal-fired power generation capacity will reach to 6 trillion $\mathrm{kw} / \mathrm{h}$ and the consumption situation of RE electricity will be more critical in the future.

TABLE II. CHINA 'S ENERGY STRUCTURE IN 2013 AND 2020 (PREDICTION)

\begin{tabular}{|c|c|c|}
\hline Energy & $\mathbf{2 0 1 3}$ & $\mathbf{2 0 2 0}$ \\
\hline Coal & $68 \%$ & $62 \%$ \\
\hline Oil & $17 \%$ & $13 \%$ \\
\hline Natural gas & $5 \%$ & $15 \%$ \\
\hline Non - fossil resource & $10 \%$ & $10 \%$ \\
\hline
\end{tabular}

\section{COMPARISON BETWEEN FEED-IN TARIFF AND RENEWABLE PORTFOLIO STANDARD}

Many countries in the promotion of RE power development, almost all use the market mechanism to promote the implementation of its policies. There are two kinds of tariff mechanism, Feed-in Tariff (FIT) and Renewable Portfolio Standard (RPS), which are respectively applied by different countries. In this case, different policy effects are also produced.

\section{A. Feed-in Tariff (FIT)}

Feed-in Tariff (FIT) is a policy used as a support mechanism to accelerate investment in RE technologies, and requires power grid enterprises to purchase RE power within a certain period of time according to a certain price. FIT offers a long-term purchase agreement for the sale of RE electricity [1]. Through direct price control instruments to make up for market failure led to the imbalance of resource allocation, and promote the RE power generation industry to achieve the sustainability of society. The operating mechanism is shown in Figure II. The government is obliged to connect independent power producers to the grid and give some incentives [2]. Power grid companies receive a fixed and guaranteed tariff from the government to purchase renewable electricity, and then, gaining profits from consumers by providing them. FIT was originated in Germany. From the scope of applications, FIT is the most widely used, the most common, and the most successful mechanism. This policy has been adopted by 20 out of the 27 countries of European Union (EU). China uses the benchmark FIT mechanism in RE, such as wind power, photo-voltaic power.

The three key factors for successful implementation of FIT are the preferential tariff quota for RE, the validity period of purchase contracts and the apportionment mechanism of the margin between RE and conventional energy. The sustained and stable cost compensation mechanism is the key to attract investors to develop RE and is the fundamental solution to overcome the barrier of high costs. China has initially established a policy to support RE electricity, so RE producers and power grid companies can enjoy reasonable tariff subsidies.

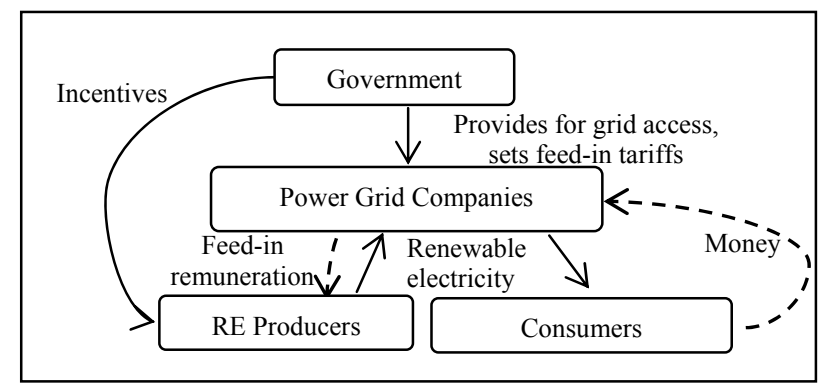

FIGURE II. SCHEME OF A FEED-IN TARIFF SYSTEM

\section{B. Renewable Portfolio Standard (RPS)}

Renewable Portfolio Standard (RPS) is the government's policy to nurture the RE market, to guarantee a minimum level of RE power generation. Grid enterprises are required to conventionally sale the power and it is necessary to sell a prescribed amount of RE power at the same time, that is to use the legal form of RE power generation market share to make mandatory [3]. Since the 20th century 80 years, California and other federal states in the United States, the United Kingdom and some other EU countries, Australia, Japan and India have introduced the policy. According to preliminary statistics, as of the end of 2015, the world, including the United States, Britain, Italy, the Netherlands and other 25 countries implemented different forms of RPS.

RPS is the essence of the lowest cost of renewable energy development, its implementation usually need to rely on the green certificate market. Green certificate is a commodity on this market, the supply-side is producers of renewable energy power, and the demand-side is grid enterprises committing the renewable energy quotas. $\mathrm{RE}$ generators will receive government-issued green certificates for every unit of 
electricity, and they can sell them on the green certificate market. The value of the green certificate represents the difference between the price of the RE electricity and the conventional energy electricity, and varies with regions and the level of RE technology.

\section{Comparison}

\section{1) Economic feasibility}

The feed-in tariff method belongs to the price policy. RE feed-in tariffs is higher than the conventional fossil energy power. The difference between them is mainly from government subsidies. The government has a high degree of control over the total amount of RE electricity subsidies, which not only increases the government's financial burden, but also increases the corresponding management costs. RPS uses the market mechanism to determine the price of green certificate [4]. The free competition market will be configured with a low enough price of green certificate to ensure that the production of new energy can be profitable at this price .At least to recover its production costs, but also to avoid the heavy fund-raising work of government. Therefore, RPS is more economic feasibility than FIT in theory.

\section{2) Market initiative}

FIT is led by the Government, lack of sufficient capacity to create a liberalized, unified electricity market [5]. RE power purchase price is higher than conventional energy power so that grid companies still want to buy cheap thermal power to earn a broader profit margin, which is easy to dampen the incentives of power producers to develop RE. The biggest advantage of RPS is that the market mechanism can provide a given amount of renewable energy at the lowest cost. Qualified power generation companies can sell green certificates to receive additional benefits through the green certificates market; Power grid companies can complete their obligations at the same time, and benefit through certificate trading to further promote RE development by introducing green certificate market; Other enterprises or individuals can purchase a green certificate through voluntary purchase, so as to mobilize the enthusiasm of the whole people to develop RE.

\section{3) Policy effectiveness}

If taking the annual or cumulative new energy installed capacity and the total installed capacity as important indicators to measure the effectiveness of policies, FIT has more advantages undoubtedly [6]. In wind power, China has become the largest wind power in the world, and the United States is ranked second. However, China's renewable energy is growing from the initial stage to mature and has a certain size now. The main problem is the consumption of $\mathrm{RE}$, so the main goal is to achieve full acquisition of RE. RPS has dual attributes between mandatory requirements and marketability, which is easier to expand the market and reduce costs.

\section{4) Technological progress}

According to European Commission report, FIT cannot reflect the changes in RE technologies flexibly, but RPS can do this and stimulates enterprises' technological innovation effectively. In terms of motivation, FIT protects the stable income of power generation companies at a fixed price, but it cannot stimulate to update the transformation of equipment and to create new technologies. However, RPS can arouse power generation companies to sell green certificates with advanced technology, to create lower costs and to promote technological progress. Johnstone, Hascic, and Popp used various types of $\mathrm{RE}$ patents as a measure of technological innovation, and analyzed the impact of various regulation policies on RE technology innovation in 25 developed countries from 1978 to 2003 [7]. The results confirmed that RPS and other types of policies had contributions on RE technology innovation.

\section{How to AChiEve Full ACQUisition of Renewable ENERGY BASED ON QUOTA SYSTEM}

Australia is the first nation to continue to implement the renewable portfolio standard (RPS) in nationwide. The Renewable Energy Bill of 2000 set out mandatory renewable energy targets. To 2010, renewable energy power was up to $9500 \mathrm{GW} / \mathrm{h}$ in the annual production of electricity, accounting for $12 \%$ of the total generating capacity of the country [8]. Table III shows the implementation phase of the Australian quota system with its corresponding implementation results and expectations. After the implementation of quota system, RE electricity hasn't increased rapidly but is lower than before. In the early development, the market mechanism is not yet mature but RE electricity has great development at a high speed in the extended period. This is due to the equitable system of Renewable Energy Certificates (RECs). RE producers can receive 1 unit of certificate for each additional $1 \mathrm{MW} / \mathrm{h}$ of $\mathrm{RE}$ electricity in addition to their obligations, which can be traded on the National Electricity Market (NEM). A fine of 40 cents REC will be absolved only if sufficient RECs are handed in. These fine funds can be incentive funds and help complete the task flexibly.

TABLE III. IMPLEMENTATION EFFECTS OF QUOTA SYSTEM IN AUSTRALIA

\begin{tabular}{|c|c|c|c|}
\hline $\begin{array}{c}\text { Electricity } \\
\text { Mechanism }\end{array}$ & $\begin{array}{c}\text { Before } \\
\text { Implementation }\end{array}$ & $\begin{array}{c}\text { After } \\
\text { Implementation }\end{array}$ & $\begin{array}{c}\text { Extended } \\
\text { Period }\end{array}$ \\
\hline $\begin{array}{c}\text { Amount of RE } \\
\text { Electricity (TW/h) }\end{array}$ & 15000 & 9500 & 35500 \\
\hline
\end{tabular}

By drawing lessons from the international experience of the United States, Australia and other countries, China can introduce RPS in order to implement the full protection of renewable energy acquisition. The framework of RPS should include the institutional basis, namely the Renewable Energy Law, the market policy, namely the green certificate market, and the quota system with supporting policies. Based on Renewable Energy Law, designing a frame clarifies the regulatory responsibilities of the government and the quota obligations of RE producers and power grid companies. The goal is to focus on solving the problem of market consumption for RE power generation and to ensure the realization of the total amount of RE in China. The framework of RPS to achieve the full acquisition is shown in figure III. 


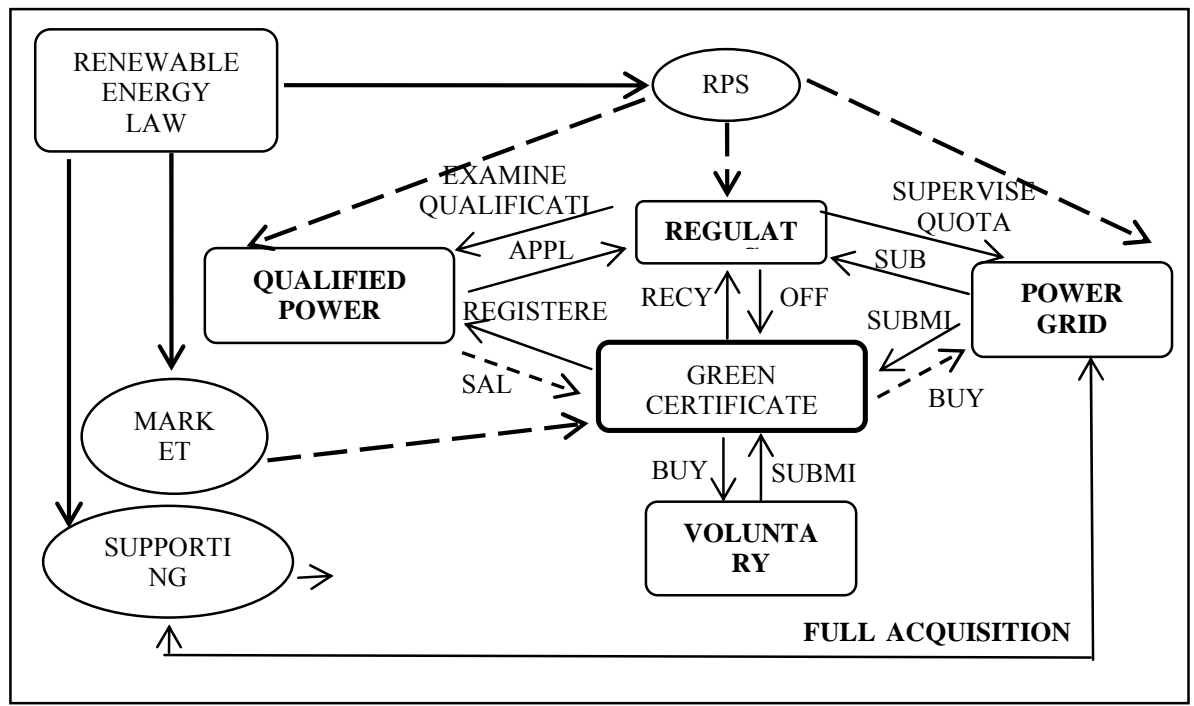

FIGURE III. THE FRAMEWORK OF RE FULL ACQUISITION ON RPS

For the electricity produced, qualified powers producers receive green certificates through the government's qualification examination, and can registered and sell them in the green certificate market. At the same time, power grid companies need to purchase green certificates to complete quota obligations set by government, and then submit green certificates to the government. Other voluntary purchasers can also participate in them. Obviously, the whole process is operated by green certificate market, the value of the certificates depends on offer and demand in the certificate market, the price is the result of both sides after the game. Therefore, the rich RE power in western can obtain benefits by the green certificate market and the high-load eastern region can also realize the demand of green electricity. Apparently, the green certificate market has coordinated the links of generation, supply and sell, which is good for solving the problem of full acquisition of RE.

Moreover, relevant supporting policies can reduce the burden of the initial investment, such as economic incentives, tax incentives and cost allocation policies. Subsidies aim to provide production incentives for energy consumed by private individuals, companies or public institutions. Money is usually provided from the government budget or from stake banks. In the case of promotion through fiscal incentives, RE producers can reduce tax burdens, which will encourage them to promote the production and acquisition of renewable energy and achieve the full acquisition of RE finally.

\section{CONCLUSION}

Faced with the change of climate, the rampant haze, and the serious phenomenon of abandoned wind, solar and water power in the transmission and distribution of them, the full acquisition of RE is difficult but imperative. FIT and RPS have good effects in many countries, but there are big differences between them. Combining the basic national conditions of China's electric power reform, RPS is the trend of RE development. Using the green certificate market, designing a rational frame of RPS and combining with some supporting policies is a good choice to solve the difficulty of RE consumption and to achieve the full acquisition of RE.

\section{ACKNOWLEDGEMENT}

This research was Supported by National Social Science Foundation Project: The Pricing Mechanism and Supporting Policies Research on Renewable Energy's Full Acquisition (14BJY143, 2014-2017) and Hunan Social Science Foundation Project: Development Strategy Research on Formation Mechanism of Electricity Price and the Transformation of Power Intensive (13ZDB26, 2012-2014).

\section{REFERENCES}

[1] Abolhosseini S, Heshmati A. The main support mechanisms to finance renewable energy development [J]. Renewable \& Sustainable Energy Reviews, 2014, 40:876-885.

[2] Shi Dan, Yang Shuai. Study on the Policy of Perfecting the Price of Renewable Energy [J] .Pricing Theory \& Application, 2012 (6): 24-28.

[3] Gboney W. Policy and regulatory framework for renewable energy and energy efficiency development in Ghana [J]. Climate Policy, 2009, 9(5):508-516.

[4] Li Yang. Study on the Price Mechanism of Renewable Energy Power Generation under Market Reform [J]. China Electric Power, 2016, 49 (3) 119-122.

[5] Tamós M M, Bade Shrestha S O, Zhou H. Feed-in tariff and tradable green certificate in oligopoly [J]. Energy Policy, 2010, 38(8):4040-4047.

[6] Jonathan A. Lesser, Xuejuan Su. Design of an economically efficient feed-in-tariff structure for renewable energy development [J]. Energy Policy, 2008, 36:981-990.

[7] Abdmouleh Z, Alammari R A M, Gastli A. Review of policies encouraging renewable energy integration \& best practices [J] Renewable \& Sustainable Energy Reviews, 2015, 45:249-262.

[8] Zhou Shao peng. Australia's renewable energy quota system and its enlightenment to China [J]. China Energy, 2012, 34 (2): 29-33. 